\title{
PENGARUH MOTIVASI TERHADAP MAHASISWA DALAM PENGGUNAAN E-LEARNING DI MASA PANDEMI COVID-19
}

\section{Fahmi BN Fuad Alamudi, Wahyu Andhyka Kusuma}

Universitas Muhammadiyah Malang (UMM) Jawa Timur, Indonesia

Email: F_amoudiii@webmail.umm.ac.id,Wahyukusuma@umm.ac.id

\begin{tabular}{l}
\hline INFO ARTIKEL \\
\hline Diterima \\
25 Agustus 2021 \\
Direvisi \\
07 September 2021 \\
Disetujui \\
15 September 2021 \\
\hline Kata Kunci: $e-$
\end{tabular}

Kata Kunci: $e$ learning; motivasi $e$ learning; motivasi belajar; pandemi covid-19
Keywords: $e$ learning; e-learning motivation; motivation to learn; covid-19 pandemic

\begin{abstract}
ABSTRAK
Penelitian ini adalah merupakan penelitian deskriptif kualitatif yang mengkaji tentang keefektifan e-learning pada pembelajaran mahasiswa pada masa pandemi. Pembelajaran jarak jauh ini akibat terdampak pandemi covid-19 yang mengharuskan mahasiswa tidak memperoleh pembelajaran tatap muka. E-learning Merupakan sistem pembelajaran jarak jauh yang mengharuskan para mahasiswanya tetap melakukan pembelajaran meskipun tidak bisa melakukan pembelajaran tatap muka. Keefektifan juga perlu dalam sebuah pembangunan sistem pembelajaran karena dalam sistem pembelajaran keefektifan itu sangat berperan penting untuk berjalannya sistem tersebut, Jika tanpa adanya keefektifan dalam suatu pembelajaran maka akan sulit bagi pengajar maupun yang mahasiswa. Pandemi merupakan wabah penyakit yang terjadi pada seluruh dunia, dengan adanya pandemi ini bidang pendidikan mengalami kesulitan untuk melakukan pembelajaran tatap muka, maka cara pemerintah untuk menanggulangi efek menyebar dari pandemi ini diterapkannya sistem pembelajaran online atau yang bisa disebut E-learning.
\end{abstract}

\section{ABSTRACT}

This research is a qualitative descriptive study that examines the effectiveness of e-learning on student learning during the pandemic. This distance learning is due to the impact of the COVID-19 pandemic which requires students not to receive face-to-face learning. E-learning is a distance learning system that requires students to continue learning even though they cannot do face-to-face learning. Effectiveness is also necessary in the development of a learning system because in the learning system effectiveness plays an important role in the running of the system. If there is no effectiveness in learning, it will be difficult for both teachers and students. Due to this pandemic, the education sector is having difficulty conducting face-to-face learning, so the government's way to overcome the spreading effects of this pandemic is the implementation of an online

$\begin{array}{ll}\text { How to cite: } & \text { Alamudi, F. B. F., \& Kusuma, W. A. (2021) Pengaruh Motivasi terhadap } \\ & \begin{array}{l}\text { Mahasiswa dalam Penggunaan E-Learning di Masa Pandemi Covid-19. Jurnal Syntax Admiration } 2 \\ \text { (9). https://doi.org/10.46799/jsa.v2i9.302 }\end{array} \\ \text { E-ISSN: } & \text { 2722-5356 } \\ \text { Published by: } & \text { Ridwan Institute }\end{array}$


learning system or what can be called E-learning.

\section{Pendahuluan}

Perkembangan teknologi semakin pesat, banyak hal-hal baru yang akan terus berubah menjadi lebih baik, lebih canggih, lebih mudah, lebih cepat, dan lebih instan. Salah satunya adalah smartphone, dimana aspek-aspek yang telah disebutkan sudah mencakup di dalamnya (Siahaan \& Meilani, 2019). Dimasa pandemi covid-19 terpaksa masyarakat bertukar gaya hidup yang biasa sehingga mewajibkan semua masyarakat melaksanakan kegiatan masing-masing seperti pelajar melalui daring (e-learning) Dalam hitungan menit teknologi terbaru dapat diciptakan jauh lebih canggih dari kemampuan teknologi sebelumnya (Anugrah, 2015). Pendidikan tinggi, kunci perubahannya adalah virtualisasi yang sangat cepat dari proses didaktik, yang dimanifestasikan dengan implementasi e-learning dalam skala besar yang belum pernah terjadi sebelumnya (Kulikowski et al., 2021). Dalam pendidikan jarak menekankan mahasiswa untuk belajar mandiri dengan memakai antara lain bahan ajar yang cara penyajiannya di rancang secara khusus sehingga diharapkan dapet dipelajari secara mandiri baik sendiri maupun bersama teman, karena karena paling penting adalah strategi belajar karena dalem pelajaran jarak jauh tidak ada orang yang menyuruh belajar atau mengingatkan belajar selain diri sendiri, sehingga, pembelajar daring akan kesulitan memecahkan masalah serta tugas-tugas yang diberikannya, pembelajar daring penting untuk dapat berkomunikasi dengan pelajar lain supaya memecahkan permesalahan-permesalahan dalem pembelajaran (Syah \& Pratama, 2020). Seorang guru yang profesional harus mampu dalam melaksanakan pengabdian tugas-tugas yang di tandai dengan keahlian, baik dalam konten maupun metode pembelajaran (Zoom et al., 2020). Ada empat poin aspek-aspek motivasi belajar, Mencapai Sesuatu Peserta didik merasa terdorong untuk berjuang demi mewujudkan keinginan dan harapanharapannya. Komitmen: Komitmen adalah salah satu aspek yang cukup penting dalam proses belajar.

Dengan memiliki komitmen yang tinggi, peserta didik memiliki kesadaran untuk belajar, mampu mengerjakan tugas dan mampu menyeimbangkan tugas. Inisiatif Peserta didik dituntut untuk memunculkan inisiatif-inisiatif atau ide-ide baru yang akan menunjang keberhasilan dan kesuksesannya dalam menyelesaikan proses pendidikannya, karena ia telah mengerti dan bahkan memahami dirinya sendiri, sehingga ia dapat menuntun dirinya sendiri untuk melakukan hal-hal yang bermanfaat bagi dirinya dan juga orang di sekitarnya. Optimis Sikap gigih, tidak menyerah dalam mengejar tujuan dan selalu percaya bahwa tantangan selalu ada, tetapi setiap dari kita memiliki potensi untuk berkembang dan bertumbuh lebih baik lagi. Kemudian aspekaspek motivasi belajar menurut yaitu: Memiliki rasa ingin tahu yang besar terhadap hal baru. Oleh karena itu, selalu terdorong untuk belajar, demi mengejar cita-citanya. Kreatif, peserta didik terus berpikir dan menciptakan sesuatu yang baru, sehingga 
membuat dirinya berbeda dengan yang lainnya Menginginkan simpati dari orang tua, guru dan teman-temannya.

Sebagai manusia biasa, kita menginginkan suatu pujian sebagai bentuk penghargaan terhadap apa yang telah kita lakukan maupun kita capai. Memperbaiki kegagalan yang lalu dengan usaha yang baru. Tidak menutup kemungkinan, ketika kegagalan menghampiri kita, pasti terbesik rasa kecewa, tetapi bukan berarti membuat kita putus asa dan menyerah, melainkan harus terus berjuang demi menjemput kesuksesan kita. Merasa aman ketika telah menguasai materi pelajaran. Memberlakukan ganjaran atau hukuman sebagai akhir dari belajar. Setiap dari kita pasti telah mengetahui dan percaya bahwa ketika melakukan hal yang baik, akan mendapatkan hasil yang baik pula, begitu pun sebaliknya. Dengan memiliki pemikiran seperti ini, akan memicu peserta didik untuk terus semangat dalam belajar. Aspek-aspek di atas merupakan bagian dari sekian banyak pendorong agar pelajar memiliki keinginan untuk belajar, karena apabila peserta didik memiliki dorongan seperti aspek-aspek di atas, maka peserta didik tersebut akan mendapatkan hasil yang maksimal sesuai dengan harapannya (Cahyani et al., 2020).

\section{Metode Penelitian}

Menggunakan metode penelitian untuk mencapai tujuan juga mendapat ketelitian dan informasi andal yang dibutuhka untuk melakukan beberapa tahapan dalam penelitian (Sudaryono et al., 2020). Metode yang dipakai pada penelitian ini adalah pendekatan kualitatif dengan menggunakan metode studi literature (Syah \& Pratama, 2020), dilakukan dengan cara mencari artikel-artikel yang berhubungan dengan $e$ learning dalam masa pandemi covid -19 untuk pengembangan media pembelajaran yang kemudian dianalisis, dalam pendidikan jarak jauh adalah strategi belajar, karena dalam pembelajaran jarak jauh tidak ada orang yang menyuruh atau mengingatkan untuk belajar, selain diri sendiri. Pelajar yang mengikuti pendidikan jarak jauh mempunyai kebebasan untuk belajar tanpa harus datang dan hadir dalam sebuah pertemuan. Namun terdapat kendala-kendala yang terjadi oleh pelajar yang mengikuti pembelajaran jarak jauh, yaitu kesulitan dalam memecahkan masalah dalam materi pembelajaran, kesulitan mencari informasi tentang pelajaran yang di bahas secara pribadi serta kesulitan dengan tugas-tugas yang diberikan (Kulikowski et al., 2021). Selanjutnya untuk dapat meningkatkan semangat belajar mahasiswa dasar agar lebih aktif dalam hal belajar dan menghasilkan sesuatu yang baru, membuat profil pelajar yang menggunakan gramifikasi (Rii et al., 2020). 


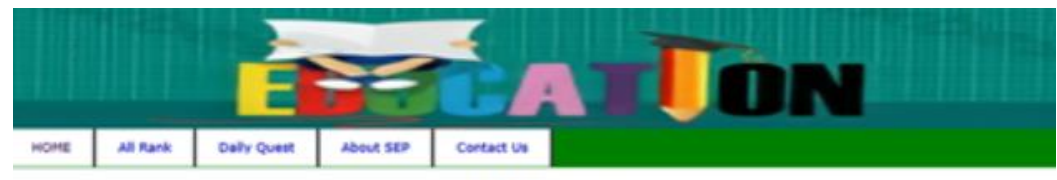

All Players
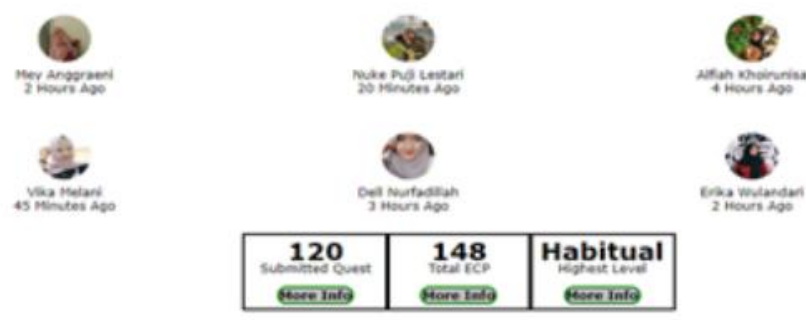

Gambar 1

Tampilan gambar e-learning (Rii et al., 2020)

Setiap kegiatan yang dilakukan di kelas akan ditampilkan pada framework. Informasi tersebut berupa total soal yang dikerjakan, score yang dicapai serta jumlah poin dari mahasiswa pada kelas (Rii et al., 2020).

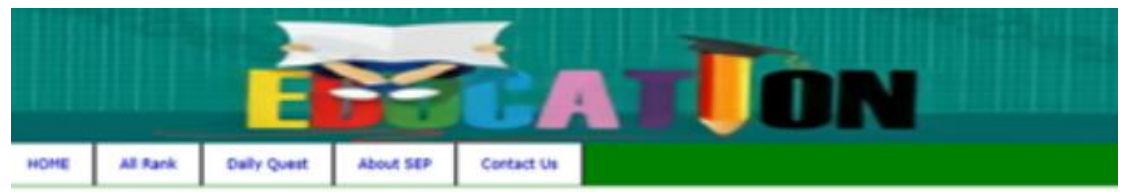

\section{Daily Quest Review}

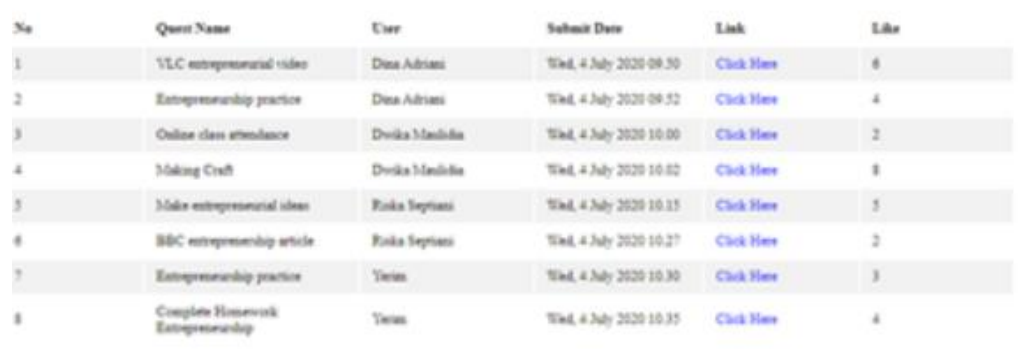

Gambar 2

Tampilan Quest Review (Rii et al., 2020)

Sistem platform ini akan menginput data kegiatan sehari-hari yang dilakukan pelajar dan kemudian dapat ditampilkan dan diakses oleh pelajar dimanapun dan kapanpun. (Rii et al., 2020) salah satu contoh Edmodo adalah sebuah platform.

Pembelajaran sosial untuk dosen, mahasiswa maupun untuk orang tua atau wali yang dikembangkan pada akhir 2008 oleh Nic borg dan Jeff O'hara yang merasakan kebutuhan untuk berkembang di lingkungan sekolah/kampus untuk mencerminkan bahwa dunia yang semakin global dan terhubung, maka membuat sebuah aplikasi yang dapat menutup kesenjangan antara bagaimana pelajar menjalani kehidupan mereka dan bagaimana mereka belajar di sekolah atau kampus. Edmodo dibuat sebagai sebuah platform pembelajaran jejaring sosial untuk guru/dosen, siswa/mahasiswa, dan orang 
tua/wali. (Mayangsari et al., 2020) Berdasarkan uraian diatas maka peneliti dapat menarik beberapa permasalahan sebagai berikut:

1. Apakah media pembelajaran Learning yang berjalan di Perguruan Tinggi saat ini belum efektif?

2. Apakah mahasiswa mendapat motivasi mendorong untuk menjalanin pembelajar tanpa putus asa?

3. Bagaimana media pembelajaran Learning dapat memudahkan dosen/mahasiswa dalam proses belajar atau mengajar?

4. Apakah media pembelajaran Learning saat ini dapat memudahkan mahasiswa sehingga proses belajar menjadi lebih efektif?

5. Apakah e-learning mengingatkan para pelajar untuk meningkat aktifitas belajar dan mengikuti kegiatan di tepat waktu? (Ariessanti et al., 2020).

Dengan adanya permasalahan diatas diharapkan sistem dapat memudahkan dosen dan mahasiswa dalam melakukan proses belajar mengajar dan juga sistem dapat menjadi wadah untuk mahasiswa dalam pengumpulan setiap tugas yang diberikan oleh dosen sehingga dosen dapat dengan mudah memantau dan melakukan penilaian dari tugas-tugas yang dikerjakan oleh mahasiswa tersebut bahkan memotivasi pengguna ketika kegiatan berjalan agar menyuport pelajar saat pandemi covid-19 dan mengingatkan mahasiswa, dosen untuk berjalan kegiatan di tepat waktu. Motivasi Elearning di sini menkankan pada kemampuan mahasiswa beradaptasi dengan lingkungan teknologi dan social sehingga penting bahwa sistem pendidikan mendukung hal tersebut (Mayangsari et al., 2020) Ketika mengintegrasikan teknologi proses pembelajaran tidak menjamin akan memotivasi mahasiswa kenyataannya E-learning berdampak pada hubungan mahasiswa dan dosen yang menajdi kurang bersosialisasi, sementara itu dosen diharapkan dapat mengakses tat kelas. Meningkat pertanyaan apa yang justru dibutuhkan para dosen untuk memotivasi mahasiswanya di lingkungan $E$ learning. (Ariessanti et al., 2020) Data yang terkumpul kemudian akan dianalisis menggunakan Paket Statistik Ilmu Sosial untuk mendapatkan hasil. Analisis frekuensi dan deskriptif akan digunakan untuk mengidentifikasi tujuan utama serta tujuan penelitian (Mahdi et al., 2020).

\section{Menentukan Stak Holder}

a) User persona mahasiswa

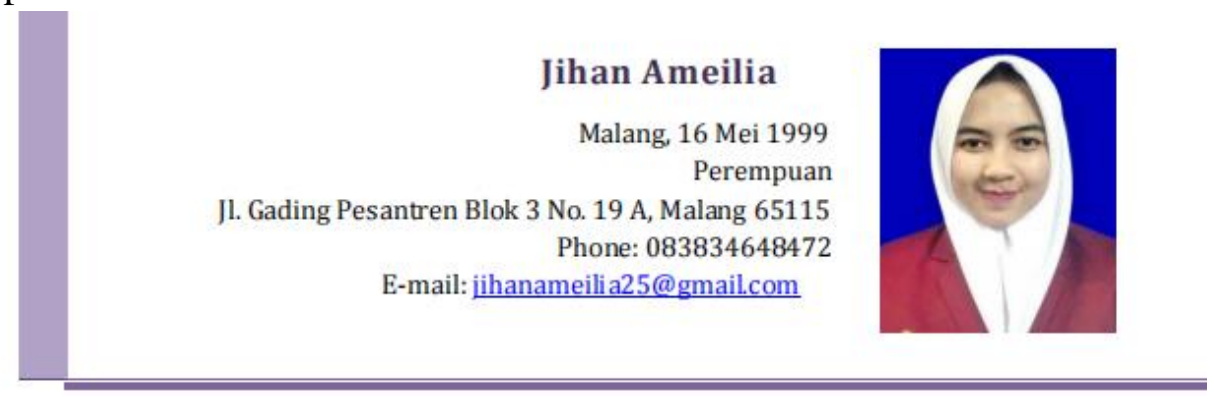


Objectives

Mahasiswa aktif Fakultas Psikologi Universitas Muhammadiyah Malang sedang menempuh semester 5 . Beretika sesuai aturan, disiplin, komunikatif, kreatif dan inovatif sudah melekat pada diri saya.

Education

\begin{tabular}{|l|l|l|}
\hline \multicolumn{1}{|c|}{ Institution } & \multicolumn{1}{c|}{ Description } & \multicolumn{1}{c|}{ Year } \\
\hline $\begin{array}{l}\text { SDN Percobaan 1 Malang } \\
\text { (Elementary School) }\end{array}$ & & $2007-2012$ \\
\hline $\begin{array}{l}\text { SMP Negeri 1 Malang } \\
\text { (Junior High School) }\end{array}$ & & $2012-2015$ \\
\hline $\begin{array}{l}\text { SMA Negeri 10 Malang } \\
\text { (Senior High School) }\end{array}$ & IPS & $2015-2018$ \\
\hline Universitas Muhammadiyah Malang & S1 Psikologi & $\begin{array}{l}\text { 2018- } \\
\text { sekarang }\end{array}$ \\
\hline
\end{tabular}

Experience

2018- sekarang

- Sebagai anggota Bulutangkis MBC

- Mendirikan usaha jual beli pakaian

- Anggota Gita Bahana Nusantara Kota Malang 2016-2018

- Sebagai sekretaris organisasi Badan Dakwah Islam

- Pembawa acara event keislaman di sekolah

b) User persona Dosen

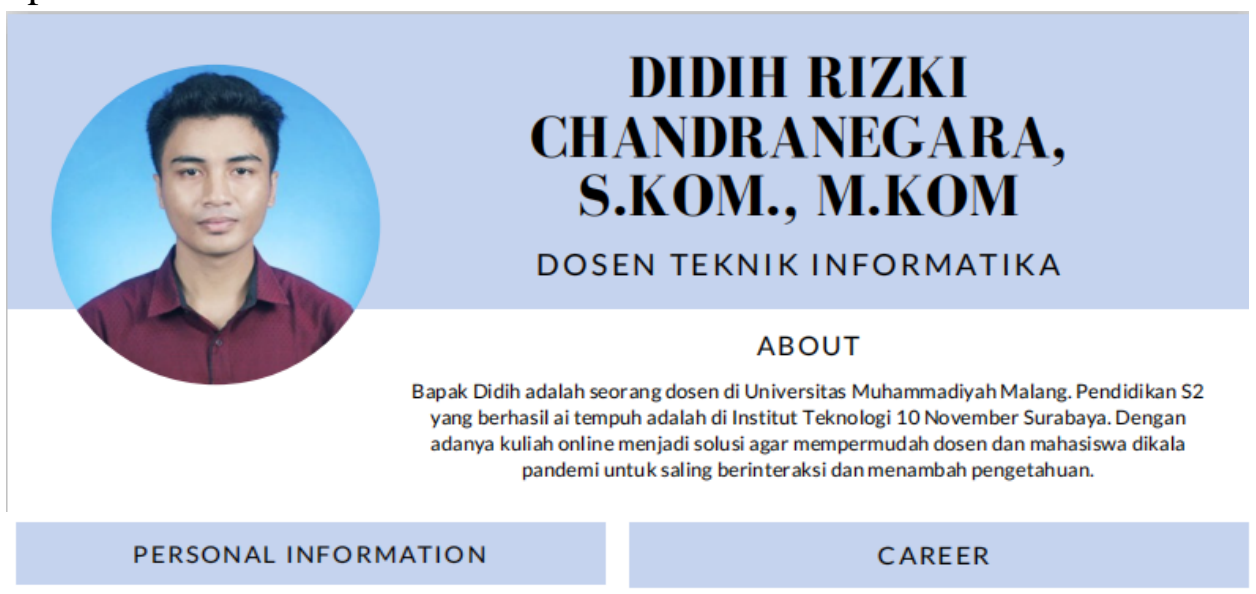

AGE :

DOSEN TEKNIK INFORMATIKA

OCCUPATION :

Universitas Muhammadiyah Malang

Dosen Teknik Informatika

STATUS:

Married

NATIONALITY :

INDONESIA

ACADEMIC HISTORY

LOCATION :

- S1 di Universitas Muhammadiyah Malang

Palangkaraya

- S2 di Institut Teknologi 10 November Surabaya 
Fahmi BN Fuad Alamudi, Wahyu Andhyka Kusuma

\section{FRUSTRATIONS}

Semua penialaian itu tidak semua bisa dilakukan dalam kondisi seperti ini, Mungkin ada beberapa yang bias dilakukan. Untuk penilaian dari ketiga aspek itu dari dosen memberikan tugas, uts, quiz, uas. Untuk saat ini dari dosen tidak bisa menilai selain aspek penilaian yang sudah disebutkan. Dan satu lagi yaitu pratikum, cuma 5 penilaian itu saja yang bisa urai menjadi ketiga as pek itu.
CONTACT INFORMATION:

Phone: $+62813-4925-4787$

Email:didihrizki@umm.ac.id

Instagram:@didih02

\section{Hasil dan Pembahasan}

\section{A. Hasil Penelitian}

Tabel 1

Variabel Latar Belakang Responden (Mahdi et al., 2020) Variables $\quad$ Percentage (\%) No. of Respondents

\begin{tabular}{lcc}
\multicolumn{1}{c}{ Percentage (\%) } & No. of Respondents \\
\hline Program & & \\
\hline BA111/BM111 & 33.7 & 61 \\
\hline BA119/BM119 & 54.7 & 99 \\
\hline AT110 & 3.3 & 6 \\
\hline AT117 & 18.3 & 15
\end{tabular}

\section{Digital Platform used}

during the E-learning

\begin{tabular}{lcc}
\hline WhatsApp & 98.9 & 179 \\
\hline Telegram & 71.3 & 129 \\
\hline UFuture & 33.1 & 60 \\
\hline LearnPortal & 42 & 76 \\
\hline Email & 51.9 & 94 \\
\hline Postage & 3 & 1.7 \\
\hline Google Meet & 83.4 & 151 \\
\hline Google Classroom & 95.6 & 173 \\
\hline Microsoft Team & 3.3 & 6 \\
\hline Microsoft Kaizala & 0 & 0 \\
\hline Zoom & 8.8 & 16 \\
\hline Voice notes (Voice & 34.3 & 62 \\
messaging) & & \\
\hline Facebook & 23.3 & 42 \\
\hline YouTube & 23.2 & 42 \\
\hline Video & 0 & 0 \\
\hline Twitter & 1.7 & 3 \\
\hline Instagram Live & 6.7 & 12 \\
\hline Webex & 5.5 & 10 \\
\hline Hangouts & 2.2 & 4 \\
\hline Phone Call & 3.3 & 6 \\
\hline Kahoot & 3.3 & 6 \\
\hline Edmodo & & \\
\hline Devices use for $\boldsymbol{E}$ - & & 176 \\
\hline learning & 3.9 & 156 \\
\hline Handphones & 97.2 & \\
\hline Notebook/Laptop & 14.4 & \\
\hline Desktop/PC & 36.2 & \\
\hline Tablet & & \\
\hline & & \\
\hline
\end{tabular}




\begin{tabular}{lcc}
\hline $\begin{array}{l}\text { Rate your Internet } \\
\text { Connection }\end{array}$ & & \\
\hline Excellent & 9.9 & 18 \\
\hline Good & 29.8 & 54 \\
\hline Not Stable & 44.2 & 80 \\
\hline Weak & 11.6 & 21 \\
\hline Very Weak & 4.4 & 8 \\
\hline
\end{tabular}

\section{B. Pembahasan}

Tabel 1. menunjukkan informasi dasar responden untuk penelitian ini, sebagian besar responden adalah mahasiswa program Diploma sebanyak 54,7 persen disusul mahasiswa dari BA111 / BM111 yaitu Program Studi Diploma Bisnis sebesar 33,7 persen. AT110 mewakili dengan 3,3 persen dan AT117 menjawab 18,3 persen. Platform digital mengacu pada media yang digunakan oleh dosen untuk menyampaikan $e$-learning dan dari tanggapan responden, hanya platform yang paling banyak digunakan akan digunakan. karena ke daftar platform berbeda yang tersedia untuk digunakan pendidik untuk tujuan E-learning. Lima platform teratas yang digunakan dosen untuk E-learning di antaranya adalah WhatsApp, Google Classroom, Google Meet, Telegram dan Email. (Mahdi et al., 2020) Berdasarkan variabel-variabel berikut ini menampilkan dimana sebagian besar yang menggunakan handphone, laptop atau notebook, desktop atau $P C$ dan tablet. Temuan ini menunjukkan bahwa pendidik harus menemukan platform yang bersahabat dengan perangkat yang paling sering digunakan untuk E-learning. Kekhawatiran penelitian adalah pada koneksi internet yang menunjukkan secara akumulatif 39,7 persen responden memiliki koneksi internet yang baik dan sangat baik sedangkan lebih dari setengahnya, dimana 60,3 persen responden memiliki koneksi internet yang tidak stabil, lemah dan sangat lemah (Mahdi et al., 2020).

Terdapat beberapa manfaat dari e-learning 1. Fleksibel, karena waktu dan tempat untuk mengakses dapat dipilih 2. Belajar mandiri, siswa memegang kendali atas keberhasilan belajar yang dilakukan 3. Efisiensi biaya, karena tidak adanya biaya penyelenggaran Kegiatan Belajar Mengajar dan Biaya Transportasi dan akomodasi bagi mahasiswa.

Setelah hampir satu tahun perkuliahan daring yang dilakukan, (Rahardja et al., 2019) banyak sekali keluhan yang diberikan oleh mahasiswa dari tugas yang menumpuk hingga adanya pengajar yang hanya memberikan tugas tanpa adanya penjelasan materi. Berikut beberapa keluhan mahasiswa di beberapa Universitas mengenai perkuliahan e-learning : 1. IAIN Bengkulu pada Dalam jurnal dijelaskan beberapa permasalahan yang dihadapi mahasiswa, antara lain : (1) Dosen hanya memberikan tugas via Whatsaap, (2) Buruknya koneksi jaringan, (3) Minimnya sarana dalam menjelaskan materi dan (4) Tidak semua dosen dapat menggunakan aplikasi SIAKAD (e-learning IAIN), Google Classroom dan Zoom Meeting.

2. Universitas Lampung (Unila) pada artikel milik Beberapa mahasiswa di dalam artikel ini menjelaskan beberapa kendala yang dihadapi, antara lain : (1) 
Jaringan internet yang lelet (2) Dosen kasih materi langsung beserta tugas sehingga mahasiswa gagal paham (3) Materi diberikan via voice note dan bukan video pembelajaran dan (4) Mahasiswa kekurangan kuota internet.

3. IAIN Tulungagung pada artikel milik Permasalahan perkuliahan daring yang dialami, diantaranya : (1) Sinyal yang sering bermasalah (2) Kurangnya pemahaman terhadap materi yang diberikan (3) Tugas yang diberikan dosen menjadi lebih banyak dan (5) Infrastruktur kampus yang belum memadai.

4. Universitas Malikussaleh (Unimal) pada artikel milik Pada artikel tersebut dijelaskan beberapa permasalahan yang dihadapi mahasiswa, yaitu : (a) Kebosanan dengan sistem (b) Banyaknya tugas yang diberikan dosen (tugas menggambar, meringkas buku atau membuat karangan sendiri) dengan sistem pembelajaran yang minim (c) Rindu untuk bertemu dengan teman-teman (d) Kurangnya kuota serta sinyal internet yang tidak stabil (e) banyak jadwal perkuliahan yang tidak sesuai kalender perkuliahan. (Eye \& Prevention, 2021) 7 (tujuh) tips mengajar dari Mendikbud di masa pandemi Covid-19, antara lain :

1) Jangan stress dalam melakukan pengajaran, cobalah keluar dari zona nyaman dan mencoba hal baru dalam metode pengajaran.

2) Melakukan penyampaian materi kepada siswa dengan sistem kelompok kecil atau dengan membagi kelas menjadi beberapa kelompok.

3) Mencoba membuat project based learning dengan kelompok-kelompok yamh telah terbentuk.

4) Pengajar harus bersedia meluangkan waktu ekstra untuk mahasiswa yang tidak dapat mengikuti pelajaran yang diberikan.

5) Pengajar harus dapat membagi-bagi konsep dasar materi agat mahasiswa dapat mengejar ketertinggalan di sekolah selain terkendala dengan alokasi waktu.

6) Adanya kerjasama dan interaksi sesama pengajar untuk bertukar pikiran dan memperoleh informasi mengenai kekurangan serta kelebihan metode mengajar yang dilakukan.

7) Buatlah pembelajaran yang sangat menyenangkan bagi mereka. Tujuannya tidak lain adalah untuk membuat materi yang disampaikan lebih efektif kepada para siswa (Al-Fraihat et al., 2020).

Persepsi mahasiswa terhadap penggunaan Zoom Data angket tanggapan siswa terhadap penggunaan Zoom dalam pembelajaran sebagaimana Tabel. Berdasarkan perhitungan diperoleh rerata nilai untuk semua indikator mencapai rentang Zoom, artinya secara umum penggunaan Zoom sangat positif dalam pembelajaran. Secara berurutan dari tertinggi ke terendah, indikator yang paling banyak dipilih Mahasiswa adalah kemenarikan tampilan Zoom, kemudahan media Zoom, ketertarikan pada Zoom, kemampuan membantu pemahaman, kemudahan memahami arahan dosen, menguatkan dorongan untuk menghafal, dan kemudahan menghafal (Cochran-Smith, 1999).

Peranan Teknologi Informasi Dalam Dunia Pendidikan Di Indonesia Komunikasi Komunikasi yang dilakukan dalam proses pendidikan dilakukan dengan 
menggunakan media komunikasi seperti telepon, komputer, internet, email dan sebagainya. Tidak hanya dalam media komunikasi, proses interaksi antara guru atau dosen dengan siswa atau mahasiswa tidak hanya bertatap muka tetapi juga dapat dilakukan melalui media tersebut dengan istilah e-learning karena model pembelajaran yang menggunakan media teknologi komunikasi dan informasi dengan menggunakan internet (Rahardja et al., 2019).

Fungsi Teknologi Informasi dan Komunikasi dalam pembelajaran Teknologi Informasi dan Komunikasi (TIK) memiliki tiga fungsi utama yang digunakan dalam kegiatan pembelajaran, yaitu: 1 . Teknologi yang berfungsi sebagai alat, yang berarti sebagai alat bantu bagi siswa dalam pembelajaran, misalnya dalam mengolah kata, angka, unsur grafis bahkan membuat database. 2. Teknologi yang berfungsi sebagai ilmu pengetahuan, yang berarti sebagai alat bantu bagi siswa untuk mencari atau mendapatkan sebuah pengetahuan dalam teknologi. Misalnya, teknologi komputer yang dipelajari bagi beberapa jurusan yang ada di sebuah perguruan tinggi contohnya ilmu komputer, informatika dan manajemen informasi. 3. Teknologi yang berfungsi sebagai bahan dan alat bantu untuk pembelajaran, yang berarti teknologi dimaknai sebagai media bahan ajar yang tentunya sudah dibekali dan di program dengan sedemikian rupa sekaligus kompetensi dalam menguasai komputer. Dalam hal ini posisi teknologi dapat sebagai guru yang berfungsi sebagai: fasilitator, motivator, transmiter, dan evaluator.

\section{Kesimpulan}

Wabah covid-19 mengharuskan setiap kegiatan pembelajaran dilakukan dengan daring. Sehingga dosen dan mahasiswa tidak dapat bertatap muka secara langsung dalam kelas tetapi harus dengan perantara teknologi informasi. Situasi baru yang harus dihadapi mahasiswa ini memberikan dampak pada motivasi belajar mahasiswa. Dari hasil analisis dapat diketahui bahwa motivasi belajar mahsiswa menurun selama pembelajaran daring. Berdasarkan hasil penelitian, pembahasan serta kesimpulan yang telah dijelaskan sebelumnya, maka peneliti mengajukan beberapa saran. Pertama bagi subjek penelitian, peneliti mengharapkan agar para Mahasiswa untuk terus meningkatkan semangatnya dalam belajar, walaupun dalam kondisi seperti ini. Mengambil hikmah dan sisi positif dari situasi yang tengah di hadapi. Kedua, bagi peneliti selanjutnya yang ingin melakukan penelitian mengenai motivasi belajar siswa di tengah situasi pandemi Covid-19, untuk menambahkan variabel-variabel yang mendukung untuk mendapatkan hasil yang lebih baik. Selain itu, mungkin alangkah lebih baiknya jika subjek penelitian di perluas lagi seperti seluruh jenjang pendidikan yang ada, dengan tujuan untuk mendapatkan hasil yang luas terkait motivasi belajar. 


\section{BIBLIOGRAFI}

Al-Fraihat, D., Joy, M., Masa'deh, R., \& Sinclair, J. (2020). Evaluating E-learning systems success: An empirical study. Computers in Human Behavior, 102 (April 2020), 67-86. https://doi.org/10.1016/j.chb.2019.08.004. Google Scholar

Anugrah, S. 2015. (2015). Keaktifan Siswa Dalam Pembelajaran Hafalan Al- Qur' An Pendahuluan. Экономика Региона, September, 32. Google Scholar

Ariessanti, H. D., Warsito, A. B., \& ... (2020). Pemanfaatan Google Drive Sebagai Media Pembelajaran iLearning Pada Perguruan Tinggi Raharja. Jurnal Voi (Voice Of ..., x, 11-22. Google Scholar

Cahyani, A., Listiana, I. D., \& Larasati, S. P. D. (2020). Motivasi Belajar Siswa SMA pada Pembelajaran Daring di Masa Pandemi Covid-19. IQ (Ilmu Al-Qur'an): Jurnal Pendidikan Islam, 3 (01), 123-140. https://doi.org/10.37542/iq.v3i01.57. Google Scholar

Cochran-Smith, M. (1999). Learning to teach for social justice. Teachers College Record, 100 (5), 114-144. Google Scholar

Eye, S., \& Prevention, D. (2021). 儿童青少年近视防控需要更高质量的研究证据 1 , 23.3 (February), 36-43. Google Scholar

Kulikowski, K., Przytuła, S., \& Sułkowski, Ł. (2021). The motivation of academics in remote teaching during the covid-19 pandemic in polish universities-opening the debate on a new equilibrium in e-learning. Sustainability (Switzerland), 13 (5), 116. https://doi.org/10.3390/su13052752. Google Scholar

Mahdi, A. F., Lajim, S. F., Shamsuddin, N. E., \& Kanyan, A. (2020). Effect of ELearning towards University Students Motivation. Borneo International Journal EISSN 2636-9826, 3(1), 8-13. Google Scholar

Mayangsari, D., Munawaroh, M., Hanafi, A., \& Fany, M. E. (2020). Redesign ELearning Edmodo Untuk Meningkatkan Semangat Belajar. Jurnal Simantec, 8 (2), 94-99. https://doi.org/10.21107/simantec.v8i2.8901. Google Scholar

Rahardja, U., Lutfiani, N., Harahap, E. P., \& Wijayanti, L. (2019). iLearning: Metode Pembelajaran Inovatif di Era Education 4.0. Technomedia Journal, 4 (2), 261-276. https://doi.org/10.33050/tmj.v4i2.1010. Google Scholar

Rii, K. B., Choi, L. K., Shino, Y., Kenta, H., \& Adianita, I. R. (2020). Application of iLearning Education in Learning Methods for Entrepreneurship and Elementary School Student Innovation. Aptisi Transactions On Technopreneurship (ATT), 2 (2), 131-142. https://doi.org/10.34306/att.v2i2.90. Google Scholar 
Siahaan, Y. L. O., \& Meilani, R. I. (2019). Sistem Kompensasi dan Kepuasan Kerja Guru Tidak Tetap di Sebuah SMK Swasta di Indonesia. Jurnal Pendidikan Manajemen Perkantoran, 4 (2), 141. https://doi.org/10.17509/jpm.v4i2.18008. Google Scholar

Sudaryono, S., Aini, Q., Lutfiani, N., Hanafi, F., \& Rahardja, U. (2020). Application of Blockchain Technology for iLearning Student Assessment. IJCCS (Indonesian Journal of Computing and Cybernetics Systems), 14 (2), 209. https://doi.org/10.22146/ijccs.53109. Google Scholar

Syah, A., \& Pratama, A. (2020). Vol. 4 No. 3 Juni 2020. (Kharisma Dan Denok, 2020 ), 4 (3), 11-19. Google Scholar

Zoom, M., Pada, S., \& Kelas, S. (2020). Keaktifan Siswa Dalam Pembelajaran Hafalan Al- Qur' An Pendahuluan Seorang guru yang profesional harus mampu dalam melaksanakan pengabdian tugas-tugas yang di tandai dengan keahlian, baik dalam konten maupun metode pembelajaran. Menteri Pendidikan dan. 11 (2), 275-293. Google Scholar

\section{Copyright holder:}

Fahmi BN Fuad Alamudi, Wahyu Andhyka Kusuma (2021)

First publication right:

Jurnal Syntax Admiration

This article is licensed under:

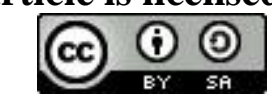

